\title{
Mechanical Complications of Peritoneal Dialysis
}

\author{
Marwa Miftah1, Mohammed Asseban², Aicha Bezzaz1, Adil Kallat², Ali Iken², \\ Yassine Nouini ${ }^{2}$, Loubna Benamar ${ }^{1}$ \\ ${ }^{1}$ Department of Nephrology-Dialysis-Kidney Transplants, Rabat Ibn Sina University Hospital, Rabat, Morocco \\ ${ }^{2}$ Urology A Department, Rabat Ibn Sina University Hospital, Rabat, Morocco \\ Email: assebanmh@hotmail.com
}

Received 27 July 2014; revised 20 August 2014; accepted 12 September 2014

Copyright (C) 2014 by authors and Scientific Research Publishing Inc.

This work is licensed under the Creative Commons Attribution International License (CC BY). http://creativecommons.org/licenses/by/4.0/

CC) (†) Open Access

\section{Abstract}

Introduction: The key to a successful chronic peritoneal dialysis is a permanent and safe access to the peritoneal cavity. The mechanical complications of peritoneal dialysis (MCPD) are a major cause of the failure of the technique. The aim of the study was to define the prevalence of peritoneal dialysis (PD) mechanical catheter complications, to determine the time and the factors associated with their occurring. Materials and Methods: A retrospective study was conducted between January 2009 and January 2014 at the nephrology, dialysis and renal transplants department of Ibn Sina university hospital in Rabat. We included all patients who were on peritoneal dialysis and presented mechanical complications. These mechanical catheter complications are represented by catheter migration or obstruction, inguinal or umbilical hernias, early and late peritoneal dialysate leakage, subcutaneous cuff extrusion and hemoperitoneum. Results: MCPD were noted in 23 of the 62 patients (37\% of cases). Onset time of complications was $24.8 \pm 18.9$ months [3 - 60 months]. Among these complications, we noted a catheter migration (65.2\%), postoperative hematoma (21.7\%), cracking or perforation of catheter (17.4\%), epiploic aspiration $(17.4 \%)$, sleeve externalization (17.4\%), catheter obstruction (13\%), hemoperitoneum (13\%), hernia $(22 \%$; $13 \%$ umbilical and $8.7 \%$ inguinal), early dialysate leakage (13\%), and pleuroperitoneal leakage (8.7\%). The average age of our patients was $54.9 \pm 15.5$ years [21 - 81 years old], with a male predominance and a sex ratio of 2.28 . The average body mass index (BMI) was $25.4 \mathrm{~kg} / \mathrm{m}^{2}$. Diabetic patients represent $48.7 \%$ of our series. In our study, MCPD represent $13 \%$ of causes of transfer to hemodialysis (HD). Conclusion: Prevention of MCPD remains crucial. It is based on good patient education on hygiene and handling errors but also periodic retraining of patients and caregivers.

\section{Keywords}

Chronic Renal Failure, Peritoneal Dialysis, Tenckhoff Catheter (TK), Insertion, Mechanical Complications 


\section{Introduction}

Peritoneal dialysis (PD) is a renal replacement technique that occupies an important place in the management of end-stage renal failure. It can be considered as a first-line treatment, temporary or permanent depending on the patient. The results of the PD in terms of morbidity and mortality are equivalent than those of hemodialysis (HD), and better in terms of quality of life [1].

The PD is introduced in Morocco for the first time in 1980, and then quickly abandoned. Through a pilot experiment at the Ibn Sina University Hospital of Rabat, started in 2006 to respond to medical and social needs, the PD was developed as a technique for renal replacement therapy [2].

The key to a successful chronic PD is a permanent and safe access to the peritoneal cavity. Indeed, the occurrence of mechanical catheter complications is a common cause of transfer to HD (8\% - 20\% of patients treated with PD); a good management of the catheter insertion and knowledge of various complications and their resolutions are paramount [3].

MCPD constitute 24\% of PD complications and are represented by catheter migration or obstruction, inguinal or umbilical hernias, early and late peritoneal dialysate leakage, subcutaneous cuff extrusion, and rarely by hemoperitoneum [4].

Contributing factors depend on each type of complication and the most contributing factor implicated in the migration of catheter is constipation. The factor implicated in hernia and fluid leakage is hyperpressure intraperitoneal.

The aim of our study was to determine the prevalence of MCPD, define their nature and identify the time and the factors associated with their occurrence.

\section{Materials and Methods}

In January 2014, we conducted at the PD unit of Ibn Sina university hospital in Rabat, a retrospective study of 5 years: from January 2009 to January 2014 we identified all patients undergoing peritoneal dialysis who presented during their follow a MCPD. Patients with infectious complications were excluded.

These complications are diagnosed by malfunction of catheter, defined by three situations:

- An impossible drainage after normal infusion;

- An impossible or incomplete drainage with slow speed after slow infusion;

- Impossible drainage and infusion.

MCPD are represented by:

- Displacement or obstruction of catheter;

- Epiploic aspiration;

- Inguinal or umbilical hernias;

- Early and late peritoneal dialysate leakage;

- Cracking or perforation of catheter and

- Hemperitoneum.

We collected from patient medical records the following variables: age, sex, initial nephropathy, duration of PD follow, number of days between insertion of PD catheter and start of exchange, onset time of complications in relation to catheter insertion.

We investigated the contributing factors of MCPD and risk factors of their occurring by comparing patients who had complications and those who did not have.

Statistically, the data were entered and analyzed using SPSS 13.0 software. Quantitative variables were expressed as mean, and standard deviation, and we used the Student t test to compare these variables. Qualitative variables were expressed as numbers and percentages and comparison was made using the Chi2 test.

\section{Implantation Technique of Peritoneal Dialysis Catheter}

The PD catheter insertion is performed in the operating room under the most stringent aseptic conditions. We use PD catheter with dacron double sleeve.

Before surgery, the patient performs a bowel preparation by a cleansing enema followed by a general toilet antiseptic (iodised polyvidone) an extensive shaving (from nipples to mid-thigh) and a thorough cleaning of the umbilicus. The site of the emergence of TK is identified preoperatively and marked on the skin taking into account the length and type of the catheter. 
Several types of anesthesia can be proposed to patients:

- The local anesthetic, frequently used, can be proposed in premedicated patients and patients's lean body weight. However, it does not control the peritoneal sensitivity and is not conducive to a good hemostasis. It often requires a stronger analgesia;

- General anesthesia which allows correct curarisation and provides comfort to the patient and the operator.

Catheter was inserted by a mini-laparotomy. The peritoneal surgical approach was lateral or paramedian to promote good attachment of deep sleeve and minimize the risk of hernias and leakage. The deep sleeve is placed in the muscles of the anterior abdominal wall or within the pre-peritoneal space. The second subcutaneous sleeve is placed near the skin and a distance of two inches from the orifice of emergence which must always be directed downward. Immediately after insertion in the operating room, the function of the catheter is verified in infusion and drainage, making sure of catheter's permeability and leaks's absence. This is done by injecting 50 $\mathrm{ml}$ of $0.9 \%$ saline. Care should be taken to never aspire injected liquid to avoid epiploic aspiration. Abdominal plain film is made two hours after waking patient to ensure the correct positioning of catheter in the pouch of Douglas.

\section{Results}

During five years, we found mechanical complications in 23 from 62 patients followed in peritoneal dialysis unit. The prevalence was 37\% after a mean period of $24.8 \pm 18.9$ months [3 - 60 months]. The initial nephropathy is shown in Table 1 . In our patients, the average age was $54.9 \pm 15.5$ years [21 - 81 years old], and the sex ratio (M/F) was 2.28 with a male predominance. The body mass index (BMI) was $25.4 \mathrm{~kg} / \mathrm{m}^{2}$. Diabetic patients accounted for $48.7 \%$. Only $4.5 \%$ of patients had undergone cesarean abdominal surgery prior to PD.

Among the mechanical complications of the RFP, we noted: catheter's migration in $65.2 \%$, postoperative hematoma in $21.7 \%$, cracking or perforation of catheter in $17.4 \%$, epiploic aspiration in $17.4 \%$, sleeve externalization in $17.4 \%$, catheter obstruction in $13 \%$, hemoperitoneum in $13 \%$, hernia in $22 \%$ (13\% umbilical and $8.7 \%$ inguinal), early dialysate leakage in 13\%, and pleuroperitoneal leakage in $8.7 \%$ of cases (Table 2).

Table 1. Initial nephropathy in patients followed in PD unit.

\begin{tabular}{cc|}
\hline Initial Nephropathy & Percentage (\%) \\
\hline Diabetic Nephropathy & $33.9 \%$ \\
Chronic Interstitial Nephritis & $16.1 \%$ \\
Chronic Glomerular Nephritis & $14.5 \%$ \\
Polycystic Kidney Disease & $9.7 \%$ \\
Undetermined Nephropathy & $25.8 \%$ \\
\hline
\end{tabular}

Table 2. Distribution of different mechanical complications.

\begin{tabular}{|c|c|c|}
\hline Mechanical Complications & Number $=23$ & $\%$ \\
\hline Catheter Migration & 15 & $65.2 \%$ \\
\hline Postoperative Hematoma & 5 & $21.7 \%$ \\
\hline Cracking or Perforation & 4 & $17.4 \%$ \\
\hline Epiploic Aspiration & 4 & $17.4 \%$ \\
\hline Sleeve Externalization & 4 & $17.4 \%$ \\
\hline Obstruction & 3 & $13 \%$ \\
\hline Hemoperitoneum & 3 & $13 \%$ \\
\hline Umbilical Hernia & 3 & $13 \%$ \\
\hline Inguinal Hernia & 2 & $8.7 \%$ \\
\hline Early Dialysate Leaks & 3 & $13 \%$ \\
\hline Pleuro-Peritoneal Leaks & 2 & $8.7 \%$ \\
\hline
\end{tabular}


The time of occurrence to complications in relation to insertion of catheter was variable and depended on several factors. Thus, the average time to catheter's migration was 4.4 months [ 0 - 20 months], to epiploic aspiration was 21 days [ 0 - 2 months], to inguinal hernia was 8 months [4 - 12 months], to umbilical hernia was 20 months [12 - 36 months], to early leakage was 3 days [0 - 6 days], to pleuroperitoneal leakage was 30 months [12 - 48 months], to cracking or perforation was 25.6 months [1 to 48] and to hemoperitoneum was 7.1 months [2 - 16 months] (Table 3).

The main contributing factor in the migration of catheter was constipation in 13 cases (86.6\%). The contributing factor to catheter obstruction was fibrin deposition in 2 cases (60\%) and blood clot in 1 case (30\%). The catheter perforation was accidental by use of sharp equipment (Table 4).

The treatment of these complications depends on mechanical contributing factors; it is either medical or surgical. Thus, treatment of the catheter migration was by transit accelerators in $80 \%$ of cases. In the remaining cases, it was surgical, either by repositioning the catheter in $13 \%$ or removal of catheter in $7 \%$ of cases.

In case of early dialysate leakage, the treatment consisted of a temporary cessation of exchanges for an average duration of 5 days. In case of pleuroperitoneal leaks, patients had a reduction in the volume of exchanges. In one patient a temporary cessation of exchanges was necessary.

Catheter cracking was treated by shortening of catheter in 2 cases and extension replacement in 2 cases.

The treatment of obstruction by a blood clot or fibrin deposition was by heparin dose of $1 \mathrm{ml} /$ liter of dialysate, while the treatment of epiploic aspiration was surgical.

Three of five patients who had a hernia (two umbilical and inguinal) underwent surgical treatment.

To evaluate risk factors of mechanical complications in PD, we compared two groups of patients, the first with mechanical complications $(\mathrm{n}=23)$ and the second without complications $(\mathrm{n}=38)$.

Univariate analysis showed that age was a protective factor of mechanical complications (Table 5).

Mechanical complications of PD KT are implicated as a cause of transfer to HD in 13\% of cases after a mean period of 13 months.

Table 3. Time to onset of mechanical complications PD.

\begin{tabular}{|c|c|}
\hline Type of Complication & Average Time \\
\hline Catheter Migration & 4.4 months $(0-20)$ \\
\hline Inguinal & 8 months (4 - 12) \\
\hline Umbilical Hernia & 20 months (12 - 36) \\
\hline Pleuro-Peritoneal Leak & 30 months (12 - 48) \\
\hline Early Leak & 3 days (0 - 6 days) \\
\hline Cracking or Perforation & 25.6 months $(1-48)$ \\
\hline Epiploic Aspiration & 21 days $(0-60)$ \\
\hline Hemoperitoneum & 7.1 months $(2-16)$ \\
\hline Obstruction & 2.2 months $(0.5-4)$ \\
\hline Sleeve Externalization & 24 months (12 - 36) \\
\hline
\end{tabular}

Table 4. Contributing factors for mechanical complications PD.

\begin{tabular}{ccc}
\hline Complications & Contributing Factor \\
\hline Migration & Constipation: 13 cases \\
Obstruction & $\begin{array}{c}\text { Fibrin Deposition: } 2 \text { cases } \\
\text { Blood Clot: } 1 \text { case }\end{array}$ \\
Perforation of Catheter & Accidentel (Sharp Equipment): 3 cases (Patient) \\
Hernia & Hyperpressure Intraperitoneal: 4 cases \\
Externalization & Catheter Traction: 2 cases \\
Hemoperitoneum & Menstruation: 1 case \\
& Anticoagulant Treatment: 1 case \\
& Abdominal Trauma: 1 case
\end{tabular}


Table 5. Risk factor for mechanical complications.

\begin{tabular}{cccc}
\hline Parameters & $\begin{array}{c}\text { No Mechanicals Complications } \\
(\mathbf{N}=\mathbf{3 8})\end{array}$ & $\begin{array}{c}\text { Mechanicals } \\
\text { Complications (N = 23) }\end{array}$ & $\boldsymbol{p}$ \\
Age & $45.4 \pm 16$ & $55 \pm 15$ & 0.033 \\
Delay (Median) & $12 \mathrm{j}$ & $7 \mathrm{j}$ & 0.717 \\
Surgical Operation & $21.1 \%$ & $4.3 \%$ & 0.087 \\
BMI kg/m ${ }^{2}$ & $24.1 \pm 4$ & $25.4 \pm 3$ & 0.37 \\
Diabetes & $23.7 \%$ & $41 \%$ & 0.116 \\
\hline
\end{tabular}

\section{Discussion}

According to Stefano et al. [5] the prevalence of mechanical complications in PD is 32.7\%, it is 30\% according to the French PD register. In our series we found a prevalence of $37 \%$, which is slightly higher.

The prevalence of catheter dysfunction varies between $0 \%-22 \%$ depending on the area, the type of catheter and insertion technique [6] [7]. Recent studies have shown that epiploic aspiration was the major cause of malfunction of catheter [8]. In our series the catheter migration was the most common cause; it represents $65 \%$ of MCPD followed by epiploic aspiration in $17.4 \%$ and catheter obstruction in 13\%.

Early complications included leakage, catheter dysfunction, hemoperitoneum, while late complications are defined by hernias, pleuroperitoneal leaks and sleeve externalization [9]-[11].

In our series the median time to onset of leakage was 3 days, of epiploic aspiration was 21 days, of catheter obstruction was 2.2 months, and of catheter migration was 4.4 months which joined the literature as early complications.

In $86 \%$ of catheter displacement, the promoting factor was constipation that we treated by transit accelerators with a success rate of $90 \%$.

Hernias of the abdominal wall are commonly observed in both the general population and in PD patients. Their number increases with age, obesity or emaciation and dehiscence of the abdominal wall. The increase of intra-abdominal pressure may be secondary to chronic constipation, bronchitis or mass syndrome (polycystic hepato-renal) [12]. The infusion of dialysate remains the main predisposing factor to hernia, the threshold for intra-abdominal pressure that must not exceed is 18 inches of water [13]. The PD population had at least two of these contributing factors.

The incidence of dialysate leaks is from $5 \%$ to $20 \%$ [14]. In our study we found dialysate leaks in five patients; three early dialysate leaks (13\% of MCPD) and two pleuroperitoneal leakages (8.7\% of MCPD). Early dialysate leaks appear in less than 30 days after catheter insertion and are often at the site of emergence [15]. In our series the time to onset of early leaks was three days after catheter insertion. Catheter leaks have two major problems: the first is temporary cessation of PD (use of hemodialysis) and the second is the risk of infection, peritonitis or infection in site of emergence [7]. In our series treatment of early dialysate leaks was temporary cessation of exchenges with an average duration of five days.

The hemoperitoneum occurs in 3\% - 4\% of the MCPD. It is considered as a benign complication and not a risk factor for peritonitis or failure of technique [16]. In our series hemoperitoneum present 13\% of MCPD after an average period of 7 months [2 to 16 months], whereas in the literature it occurs after an average period of 10.5 months [1 to 37 months].

To determine factors associated to MCPD, we have not been able to determine a significant relationship between these factors and MCPD as in the literature [17].

The externalization of the sleeve is either due to melting of edema, progressive cachexia or traction on the KT, treated by peeling the dacron. In our series we found 4 cases of externalization of the sleeve (17.4\% of CMDP), which are due in half of the cases to the traction on the KT. All patients underwent a coat.

In our series we studied the group with and the group without CMDP. We compared the age, diabetes, prior surgery and BMI of these two groups of patients so we can determine factors associated with CMDP. And as the data from the literature we were not able to determine a significant relationship between these factors and the CMDP [17].

The CMDP is the second major cause of output from the PD technique after peritonitis, it prevalence varies between $8 \%$ - 20\% of all outputs [18]. In our series the CMDP are a cause of failure of the technique in $13 \%$ of cases. 


\section{Conclusions}

The success of PD depends on a functional and sustainable peritoneal access. Successful access based primarily on the operator expertise. The catheter insertion must be done by a trained operator. The main cause of MCPD was due to displacement of catheter which is stressful for the patient and the PD team.

Many insertion techniques can be adopted, but it is recommended to entrust this practice to experienced operators who will use the technique they control the best.

The PD technique suffers from a lack of interest in Morocco in comparison with hemodialysis and renal transplantation. Its various infectious complications as well as mechanical complications do not explain its low implementation in the treatment of end-stage renal disease (ESRD). Prevention of MCPD is key; it is based on good patient education on hygiene and handling errors but also periodic retraining of patients and caregivers.

\section{References}

[1] Chanliau, J. and Kessler, M. (2011) Peritoneal Dialysis for ESRD Patients: Financial Aspects. Néphrologie \& Thérapeutique, 7, 32-37. http://dx.doi.org/10.1016/j.nephro.2010.10.004

[2] Haddiya, I., Skalli, Z., Lioussfi, Z., Radoui, A., Ouzeddoun, N., Ezaitouni, F., et al. (2010) Peritoneal Dialysis: A Satisfying Experience of a Misknown Technique in Rabatat the University Hospital. Néphrologie \& Thérapeutique, 6, 569-575. http://dx.doi.org/10.1016/j.nephro.2010.07.017

[3] Flanigan, M. and Gokal, R. (2005) Peritoneal Catheters and Exit-Site Practices toward Optimum Peritoneal Access: A Review of Current Developments. Peritoneal Dialysis International, 25, 132-139.

[4] Singh, N., Davidson, I., Minhajuddin, A., Gieser, S., Nurenberg, M., Saxena, R. (2010) Risk Factors Associated with Peritoneal Dialysis Catheter Survival: A 9-Year Single-Center Study in 315 Patients. The Journal of Vascular Access, 11, 316-322.

[5] Santarelli, S., Zeiler, M., Marinelli, R., Monteburini, T., Federico, A. and Ceraudo, E. (2006) Videolaparoscopy as Rescue Therapy and Placement of Peritoneal Dialysis Catheters: A Thirty-Two Case Single Centre Experience. Nephrology Dialysis Transplantation, 21, 1348-1354. http://dx.doi.org/10.1093/ndt/gfk041

[6] Schaubel, D.E., Blake, P.G. and Fenton, S.S. (2001) Trends in CAPD Technique Failure: Canada, 1981-1997. Peritoneal Dialysis International, 21, 365-371.

[7] Scarpioni, R. (2003) Acute Hydrothorax in a Peritoneal Dialysis Patient: Long-Term Efficacy of Autologous Blood Cell Pleurodesis Associated with Small-Volume Peritoneal Exchanges. Nephrology Dialysis Transplantation, 18, 2200-2201. http://dx.doi.org/10.1093/ndt/gfg335

[8] Zakaria, H.M. (2011) Laparoscopic Management of Malfunctioning Peritoneal Dialysis Catheters. Oman Medical Journal, 26, 171-174. http://dx.doi.org/10.5001/omj.2011.41

[9] Fleisher, A.G., Kimmelstiel, F.M., Lattes, C.G. and Miller, R.E. (1985) Surgical Complications of Peritoneal Dialysis Catheters. The American Journal of Surgery, 149, 726-729. http://dx.doi.org/10.1016/S0002-9610(85)80174-4

[10] Farooq, M.M. and Freischlag, J.A. (1997) Peritoneal Dialysis: An Increasingly Popular Option. Seminars in Vascular Surgery, 10, 144-150.

[11] Peppelenbosch, A., van Kuijk, W.H., Bouvy, N.D., van der Sande, F.M. and Tordoir, J.H. (2008) Peritoneal Dialysis Catheter Placement Technique and Complications. Nephrology Dialysis Transplantation, 1, 23-28.

[12] Morris-Stiff, G., Coles, G., Moore, R., Jurewicz, A. and Lord, R. (1997) Abdominal Wall Hernia in Autosomal Dominant Polycystic Kidney Disease. British Journal of Surgery, 84, 615-617. http://dx.doi.org/10.1002/bjs.1800840509

[13] Del Peso, G., Bajo, M.A., Costero, O., Castro, M.J., Gil, F. and Selgas, R. (2001) Mechanical Complications of Abdominal Wall in Patients Treated with Peritoneal Dialysis. Peritoneal Dialysis International, 21, $24 \mathrm{~S}$.

[14] García-Ureña, M.A., Rodríguez, C.R., Vega Ruiz, V., Carnero Hernández, F.J., Fernández-Ruiz, E., Vazquez Gallego, J.M. and Velasco García, M. (2006) Prevalence and Management of Hernias in Peritoneal Dialysis Patients. Peritoneal Dialysis International, 26, 198-202.

[15] Szeto, C.C. and Chow, K.M. (2004) Pathogenesis and Management of Hydrothorax Complicating Peritoneal Dialysis. Current Opinion in Pulmonary Medicine, 10, 315-319. http://dx.doi.org/10.1097/01.mcp.0000127901.60693.d0

[16] Tse, K.C., Yip, P.S., Lam, M.F., Li, F.K., Choy, B.Y., Chan, T.M. and Lai, K.N. (2002) Recurrent Hemoperitoneum Complicating Continuous Ambulatory Peritoneal Dialysis. Peritoneal Dialysis International, 22, 488-491.

[17] Singh, N., Davidson, I., Minhajuddin, A., Gieser, S., Nurenberg, M. and Saxena, R. (2010) Risk Factors Associated with Peritoneal Dialysis Catheter Survival: A 9-Year Single-Center Study in 315 Patients. Journal of Vascular Access, 11, 316-322. 
[18] Kolesnyk, I., Dekker, F.W., Boeschoten, E.W. and Krediet, R.T. (2010) Time-Dependent Reasons for Peritoneal Dialysis Technique Failure and Mortality. Peritoneal Dialysis International, 30, 170-177.

http://dx.doi.org/10.3747/pdi.2008.00277 
Scientific Research Publishing (SCIRP) is one of the largest Open Access journal publishers. It is currently publishing more than 200 open access, online, peer-reviewed journals covering a wide range of academic disciplines. SCIRP serves the worldwide academic communities and contributes to the progress and application of science with its publication.

Other selected journals from SCIRP are listed as below. Submit your manuscript to us via either submit@scirp.org or Online Submission Portal.
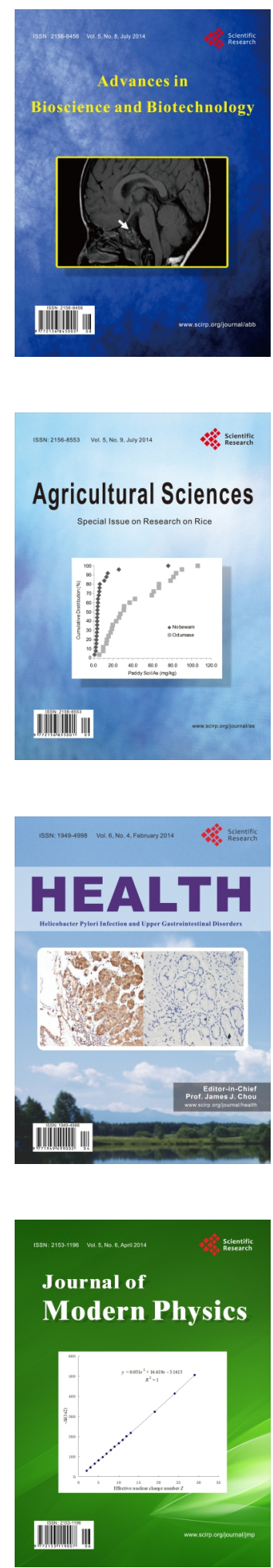
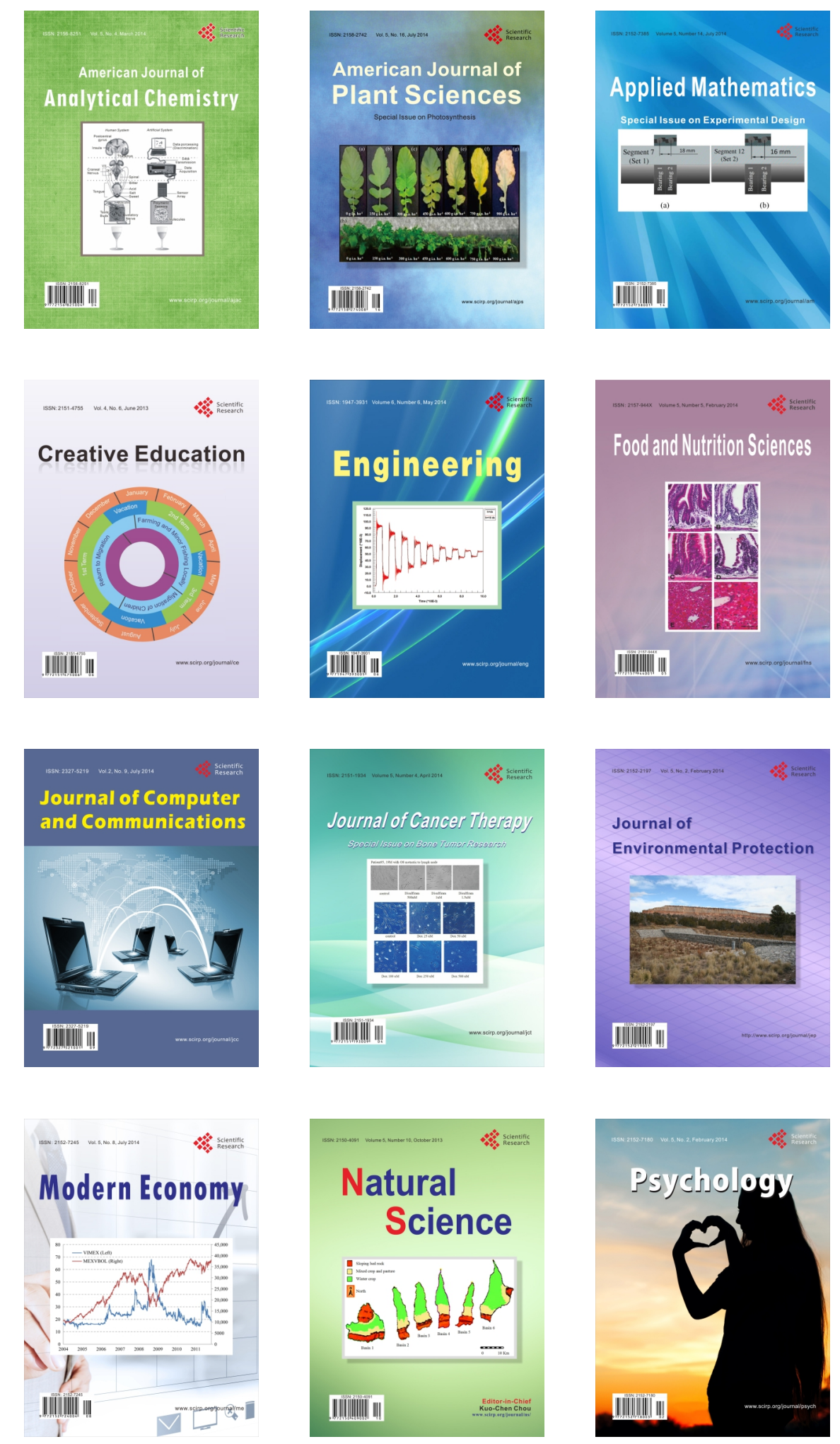